\title{
Stimulus variation and resistance to extinction: Satiation or disinhibition?
}

\author{
W. Edward Bacon and Dalbir Bindra \\ MCGILL UNIVERSITY
}

\begin{abstract}
Abstraet
Taken jointly with previous findings, the results of the present experiment on 4 groups of rats, trained and extinguished under variable or constant stimulus conditions, suggest the following tentative conclusions. When it is not so marked as to evoke interfering "novelty reactions," stimulus variation, introduced during extinction, will increase resistance to extinction. This effect is attributable to some general energizing or disinhibiting influence of stimulus variation on response tendency and is not a specific stimulus satiation effect.

\section{Problem}

The introduction of a stimulus change into an experimental extinction situation usually facilitates the extinction process (e. g., Hall, 1955), but the reverse effect has been known to occur. Brown \& Bass (1958) found that by continually varying the stimulus conditions during extinction, resistance to extinction was noticeably increased. The present study was concerned with determining the relative importance of two explanatory concepts, stimulus satiation and disinhibition, suggested by Brown \& Bass to account for their results.

Stimulus satiation refers to a decreased responsiveness (habituation) to a specific set of stimuli as a result of repeated or continued exposure to it (Glanzer, 1953). The phenomenon descriptively referred to as "disinhibition" (Pavlov, 1927) has been attributed to an increase in general responsiveness dependent upon "...the potent non-specific activating effects..." of novel stimuli (Sharpless \& Jasper, 1956, p. 666). It follows from these definitions that stimulus satiation would decrease the resistance to extinction of only those components of a response which are associated with the previously exposed stimuli, while disinhibition, by increasing responsiveness to all stimuli, would increase the resistance to extinction of all the components of the response. In the present experiment, stimulus variation was introduced only in the start box of an alleyway and its effects were determined for both the starting and running components of the response.

\section{Method}

The apparatus was a black enclosed right-turn L-shaped alleyway, 9.5 in high, which has been described in detail elsewhere (Bacon, in press). Briefly, it consisted of a long arm, 64 in long and 4 in wide, with the exception of the first 9-in unit which was 6 in wide and served as a start box, and a short arm, 14 in long and 6 in wide which served as a goal box. By means of cardboard inserts, the walls of the start box on any given trial were made either gray, black, white, or black-white vertical stripes. Starting and running times were measured to the nearest .01 sec., respectively, from the opening of the start-box door to the breaking of a photocell beam located 2.5 in from the door and from the breaking of this beam to the interruption of a second beam 42 in further down the alleyway.

The Ss, 40 experimentally naive male hooded $80-90$ day old rats, were placed on a water deprivation schedule consisting of $1 / 2-\mathrm{hr}$. access to water daily nine days prior to the start of the experiment and were maintained on this schedule throughout the experiment. On the two days preceding acquisition training, Ss were placed in the goal box in pairs on the first day and individually on the second day for $5 \mathrm{~min}$. access to water.

All Ss were given 60 trials of acquisition training and 24 trials of extinction, four trials per day. A trial consisted of placing $S$ in the start box facing the rear wall and raising the start-box door $15 \mathrm{sec}$. later. Each $\mathrm{S}$ was given 15 sec. access to water in the goal box on acquisition trials and was confined for $15 \mathrm{sec}$. without access to water on extinction trials. During extinction, any $S$ taking longer than $120 \mathrm{sec}$. to start or to run was removed from the apparatus and assigned a score of 120 for that trial.

Half the Ss received acquisition training with a gray start box and were designated the constant condition (C) group. The remaining Ss were given acquisition training with all four start boxes (gray, black, white, and black-white stripes) and were designated the varied condition (V) group. The $\mathrm{V}$ group received one trial each day with each start box, the daily order of presentation being randomly determined. For extinction, each group was further divided into two subgroups, one subgroup receiving $\mathrm{C}$ treatment, the other $\mathrm{V}$ treatment, thus yielding the following four experimental groups: $\mathrm{C}-\mathrm{C}, \mathrm{C}-\mathrm{V}, \mathrm{V}-\mathrm{C}$, and $\mathrm{V}-\mathrm{V}$ (the first letter indicates the acquisition treatment and the second letter the extinction treatment).

\section{Results}

Analyses of variance were carried out separately on acquisition and extinction starting and running times averaged in blocks of four trials. The upper portion of Fig. 1 shows that the two groups receiving varied stimulus conditions during extinction $(\mathrm{C}-\mathrm{V}$ and $\mathrm{V}-\mathrm{V})$ had lower over-all starting times; $F(1,36)=7.09 ; p<.025$; and slower rates of extinction; $F(5,180)=3139 ; p<.01$; than the two groups receiving constant conditions $(\mathrm{C}-\mathrm{C}$ and $\mathrm{V}-\mathrm{C}$ ). The lower portion of Fig. 1 shows that the varied stimulus conditions during extinction also resulted in lower over-all running times as compared to constant conditions; $F(1,36)=11.66 ; \mathrm{p}<.01$; although the extinction treatment $\mathrm{x}$ extinction trials interaction was not statistically significant; $F(5,180)=2.18 ; p>.05$. The constant vs. varied conditions treatment during acquisition had no statistically reliable effect $(p ' s>.05)$ on either acquisition or extinction starting and running time measures.

Further analyses of starting and running times led to the following conclusions. (1) During acquisition, the varied treatment $(\mathrm{V}-\mathrm{C}$ and $\mathrm{V}-\mathrm{V})$ Ss did not respond differentially to the different start boxes ( $p$ 's $>.05$ ). (2) During extinction, varied treatment $(\mathrm{C}-\mathrm{V}$ and $\mathrm{V}-\mathrm{V}) \mathrm{Ss}$ showed no over-all response time differences to the different start boxes ( $\left.p^{\prime} s>.05\right)$. (3) However, C-V Ss 

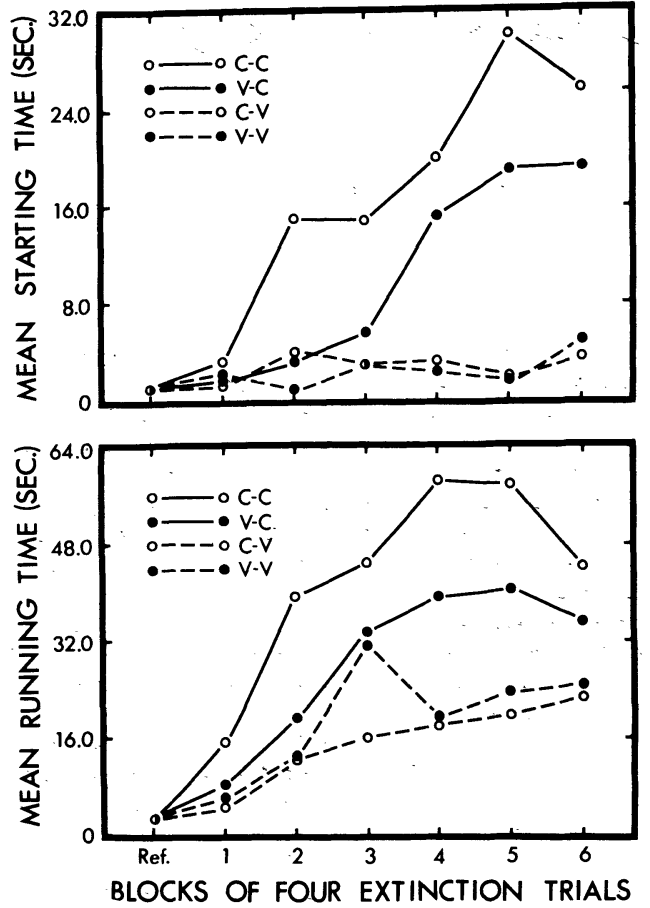

Fig. 1. Mean starting and running time across blocks of extinction trials for the four experimental groups (Ref. block indicates the means on the last four acquisition trials).

did show a small initial response decrement to novel (black, white, and black-white stripes) start boxes and a faster rate of extinction with the familiar (gray) start box (starting time, $\mathrm{p}<.10$; running time, $\mathrm{p}<.05$ ).

\section{Diseussion}

As both the starting and running time measures reflect greater resistance to extinction following varied extinction stimulus conditions as compared to constant conditions, the disinhibition interpretation seems to be supported. The stimulus satiation hypothesis would predict no running time differences between the groups as all Ss received equal exposure to runway stimuli. The obtained results can be explained on the assumption that the variation in start-box stimuli during extinction served to energize or disinhibit the organism and that this state persisted to facilitate not only the starting component (instigation) of the response but the running component as well.

Brown \& Bass reported an initial response decrement in the $\mathrm{C}-\mathrm{V}$ group when first exposed to the novel stimuli during extinction which was of much greater magnitude than that found in the present study. This leads one to speculate that while stimulus variation may serve to energize the organism during extinction such an energizing effect will be exhibited in facilitated performance only to the degree that competing responses or "novelty reactions"' (Bindra, 1961) are not evoked. Extreme stimulus changes such as those used by Brown \& Bass may obscure the disinhibition effect in the early extinction trials by evoking novelty reactions which interfere with the instrumental response. Less extreme stimulus variation, although possibly energizing the organism to a lesser extent, also evokes fewer novelty reactions.

Pursuing the disinhibition interpretation further, it seems. reasonable to assume that the degree to which Ss will be energized will be some positive function of the novelty of the stimulus. Since Claus \& Bindra (1960) have demonstrated that stimulus novelty is inversely related to the degree of prior exposure to the stimulus, resistance to extinction in the present experiment should be inversely related to the number of prior exposures (trials) to start-box stimuli. If one plots the number of prior exposures (including acquisition and extinction trials) to the extinction start box for Groups $\mathrm{C}-\mathrm{C}$ and $\mathrm{V}-\mathrm{C}$ and the average number of prior exposures to the different extinction start boxes for Groups $\mathrm{V}-\mathrm{V}$ and $\mathrm{C}-\mathrm{V}$ as a function of extinction trial blocks, the result is a set of curves in which the relative group differences and the relative rates of extinction do indeed closely resemble the obtained response times.

\section{References}

BACON, W. E. Resistance to extinction following blocking of the instrumental response during acquisition. J. exp. Psychol., in press. BINDRA, D. Components of general activity and the analysis of behavior. Psychol. Rev., 1961, 68, 205-215.

BROWN, J. S., \& BASS, B. The acquisition and extinction of an instrumental response under constant and variable stimulus conditions. J. comp: physiol. Psychol., 1958, 51, 449-504.

CLAUS, H. J., \& BINDRA, D. Reactions to novelty and stimuluschange induced response decrement. Canad. J. Psychol., 1960, 14, 101-110.

GLANZER, M. Stimulus satiation: an explanation of spontaneous alternation and related phenomena. Psychol. Rev., 1953,60, 257-268.

HALL, J. F. Experimental extinction as a function of altered stimulating conditions. J. genet. Psychol., 1955, 87, 155-158.

PAVLOV, I. P. Conditioned reflexes. London: Oxford Univer. Press, 1927.

SHARPLESS, S., \& JASPER, H. Habituation of the arousal reaction. Brain, 1956, 79, 655-680.

\section{Note}

1. The research reported in this paper was supported by a grant (APT-74) from the National Research Council of Canada to Dr. Dalbir Bindra. 